\title{
Electroreduction of p-Nitrophenol by Surfactant Modified Electrodes
}

\author{
Yong $\mathrm{Li}^{1,2}$, Yuxin Zhang ${ }^{1 *}$, Wei Xue ${ }^{1}$, Yingji Zhou ${ }^{1}$, Bo Li ${ }^{3}$, Yaping Ding ${ }^{2}$, Ruizhu Zhang ${ }^{1}$ \\ ${ }^{1}$ School of Materials science and Engineering, North China University of Water Resources and Electric Power, Zhengzhou \\ 450046, China \\ ${ }^{2}$ School of Materials Science and Engineer, and College of Science, Shanghai University, Shanghai 200444, China \\ ${ }^{3}$ School of Materials Science and Engineering, University of Science and Technology Beijing, Beijing 100083, China
}

Corresponding Author Email: zyx@ncwu.edu.cn

https://doi.org/10.18280/acsm.430509

Received: 10 May 2019

Accepted: 19 August 2019

\section{Keywords:}

p-nitrophenol, linear sweep voltammetry, surfactant, modified electrode

\begin{abstract}
This paper mainly compares the electroreduction of p-nitrophenol by different surfactantmodified chemical electrodes. Four surfactants were prepared to modify the glassy carbon electrode, including a cationic surfactant (CTAB), an anionic surfactant (SDBS) and two nonionic surfactants (Tween 80, OP-10). Each modified electrode was applied to detect the p-nitrophenol in sodium acetate buffer solution, and the reduction peak current and reduction peak potential of p-nitrophenol were measured by linear sweep voltammetry under different concentrations of each surfactant. The results show that the cationic surfactant reduced the peak current, reaching the optimal effect at the concentration of $2.95 \times 10-4 \mathrm{~mol} / \mathrm{L}$; the anionic surfactant and nonionic surfactants reduced the peak current, and the reduction effect depends on the micelle effect of the surfactants and other factors; the cationic surfactant suppressed the reduction peak potential at concentrations of $0 \sim 2 \times 10-4 \mathrm{~mol} / \mathrm{L}$, while the other three surfactants cannot reduce the reduction peak potential; the CTAB was proved as the most sensitive material for detecting p-nitrophenol on electrode surface. This research provides a valuable reference for the design of p-nitrophenol sensors.
\end{abstract}

\section{INTRODUCTION}

Many surfactants have been adopted to modify electrodes to improve their sensitivity. In recent years, the sensitization mechanism of surfactants has become a research hotspot. Below is a brief review of some of the most representative works.

Azzam et al. [1] synthesized two nanocomposite catalysts, namely, TiO ${ }_{2} @$ CNTs/AgNPs and TiO $2 @$ CNTs/AgNPs/C10, to modify electrodes, confirmed that the surfactant $\mathrm{C} 10$ improved the dispersion and surface interaction of AgNPs on $\mathrm{TiO}_{2} @ \mathrm{CNTs}$, forming an effective photocatalytic site, and found that $\mathrm{TiO}_{2} @ \mathrm{CNTs} / \mathrm{AgNPs} / \mathrm{C} 10$ exhibited superior photodegradation of methylene blue dye. Dos Santos et al. demonstrated that the DAAMPV resin could adsorb a large amount of p-nitrophenol in wastewater quickly [2-7]. some scholars discovered that the additional bio-degradation measure increases the degradation rate of $\mathrm{p}$-nitrophenol by $88.5 \%$ in soil aquifer treatment system from the level of abiotic method $[8,9]$.

With the aid of the electro-Fenton process, some scholars successfully degraded p-nitrophenol in water with CNTmodified nickel foam electrode, and concluded that the porosity of the CNT enhanced the electro-Fenton effect, making the electrode highly reusable [10-14]. Through structural and morphology analysis, related researches compared the nickel foam system and cooper foam system in p-nitrophenol degradation, and confirmed that the latter has the better degradation effect but the former has the better stability [15-21].

Vervald et al. [22] studied the influence of interactions of hydrophobic and hydrophilic nano-diamonds with ionic surfactant sodium octanoate in water on hydrogen bonds, the properties of the surfactant and micelle formation, and attributed the influence partially to the creation of the chaotic state in the surfactant solutions if two or more incompatible types of interactions between nanoparticles' surfaces and surfactants are similarly favorable, e.g. hydrophobic interaction and Coulomb attraction.

Chen et al. [23] designed a series of novel sodium medium alkyl chain PPO-b-PEO sulfates (C8PpEeS), and found that the properties of $\mathrm{C} 8 \mathrm{PpEeS}$ are dominated by the dynamic amphipathcity and assisted by the rugby ball shape of the molecules because of both being driven by the dynamic biphasic affinity of the PPO coil in response to the external environment. Karthick et al. [24] held that nanoparticle (NP) stabilized foam has emerged as an effective remediation strategy, and highlighted the necessity to investigate the effects of physicochemical properties of NP on soil remediation.

Garcia et al. [25] experimentally proved that aquatic toxicity of oligomeric cationic surfactants depends on their hydrophobicity and increases regularly with the alkyl chain length; however, whether the surfactant is a dimeric or a trimeric betaine ester does not affect their acute toxicity to crustacean. Trinh et al. [26] suggested that the attraction of surfactants to membranes is not related to the extent of membrane fouling but to the magnitude of the repulsive energy.

To sum up, the previous research on surfactant modified electrodes has concentrated on hydrocarbon bio-organisms like amino acids or carbon nanotubes. There is no report on the 
application of these electrodes on phenols. To make up for the gap, this paper modifies the glassy carbon electrode with different surfactants, and uses the modified electrode to degrade the p-nitrophenol in sodium acetate buffer solution. The reduction peak currents of $\mathrm{p}$-nitrophenol were measured at different concentrations of each surfactant.

\section{METHODOLOGY}

\subsection{Instruments and reagents}

The main instruments are as follows: CHI660D electrochemical workstation (Shanghai Chenghua); ME104 electronic balance (Mettler-Toledo); PSC-3C digital display desktop $\mathrm{pH}$ meter (Shanghai Yueping); auxiliary electrode (REX); reference electrode (REX); glassy carbon working electrode (3mm) (REX).

As for the reagents, the sodium acetate buffer was formulated with anhydrous sodium acetate; the cetyltrimethylammonium bromide (CTAB) was selected as the cationic surfactant; the sodium dodecylbenzene sulfonate (SDBS) was adopted as the anionic surfactant; Tween-80 was chosen as the nonionic surfactant; OP-10 was purchased as the emulsifier; the test water is secondary deionized water.

\subsection{Experimental procedure}

\subsubsection{Electrode preparation}

(1) Rotate the glassy carbon electrode on the suede in the shape of an eight or clockwise (counterclockwise), place a small amount of nano- $\mathrm{Al}_{2} \mathrm{O}_{3}$ powder $(0.05 \mu \mathrm{m})$ on the suede and a few drops of deionized water, and polish the electrode into a mirror surface.

(2) Immerse the polished electrode in $15 \mathrm{~mL}$ secondary deionized water, $15 \mathrm{~mL}$ 1:1 $\mathrm{HNO}_{3}$ solution, $15 \mathrm{~mL}$ absolute ethanol solution, and then in $15 \mathrm{~mL}$ secondary deionized water for $5 \mathrm{~min}$, in turn, to thoroughly clean the electrode. At this point, the desired electrode is made and ready for use.

\subsubsection{Solution preparation}

(1) Preparation of buffer solution (NaAc-HAc): Weigh about $8.2033 \mathrm{~g}$ anhydrous sodium acetate, stir it in a beaker and pour it into a $1,000 \mathrm{~mL}$ volumetric flask to obtain a $0.1 \mathrm{~mol} / \mathrm{L}$ NaAc solution; use Nac solution with HAc solution after adjusting the $\mathrm{pH}$ to 5 . The $\mathrm{pH}$ can be adjusted as needed in the experiment.

(2) Preparation of standard solution $(0.01 \mathrm{~mol} / \mathrm{L} \mathrm{p}$ nitrophenol): Take $0.1370 \mathrm{~g}$ p-nitrophenol solids, dilute them in a $100 \mathrm{~mL}$ volumetric flask, and shake the flask well. Dilute and shake stepwise before use.

(3) Preparation of surfactants $(0.001 \mathrm{~mol} / \mathrm{L}$ CTAB and SDBS): Weight $0.0914 \mathrm{~g}$ CTAB, $0.0873 \mathrm{~g}$ SDBS, $0.00910 \mathrm{~g}$ Tween-80 and $0.1617 \mathrm{~g} \mathrm{OP}-10$, and dilute them in a $250 \mathrm{~mL}$ volumetric flask and shake the flask well. Dilute and shake stepwise before use.

\section{EXPERIMENTAL RESULTS AND DISCUSSION}

\subsection{The effect of $\mathrm{pH}$}

In the $0.1 \mathrm{~mol} / \mathrm{L} \mathrm{NaAc-HAc}$ buffer solution, the $\mathrm{pH}$ was controlled by adjusting the HAc concentration, and the relationship between the peak current and the $\mathrm{pH}$ of $\mathrm{p}$ nitrophenol reduction was studied by linear sweep voltammetry. The results in Table 1 show that the peak current decreased with the growing $\mathrm{pH}$, indicating that the $\mathrm{H}^{+}$in the solution accelerates the redox reaction of p-nitrophenol.

Table 1. Relationship between peak current and $\mathrm{pH}$ value of p-nitrophenol reduction

\begin{tabular}{c|c|c|c|c|c}
\hline $\mathrm{pH}$ & 4.0 & 4.5 & 5.0 & 5.5 & 6.0 \\
\hline $1 \times \mathrm{e}^{-5} \mathrm{~A}$ & 7.212 & 6.593 & 6.233 & 6.684 & 5.565 \\
\hline
\end{tabular}

As shown in Table 1, with the decrease in the $\mathrm{pH}$ of the solution, the absolute value of the reduction characteristic peak shifted from large to small, the peak current increased continuously, and the peak maintained a good shape. These agree with the theories on the oxidation reaction with pnitrophenol. The $\mathrm{pH}$ value of 4 was taken as the acidity of the reaction system, because of the high peak current, optimal peak shape and small absolute value of the peak potential.

\subsection{Optimization of experimental conditions}

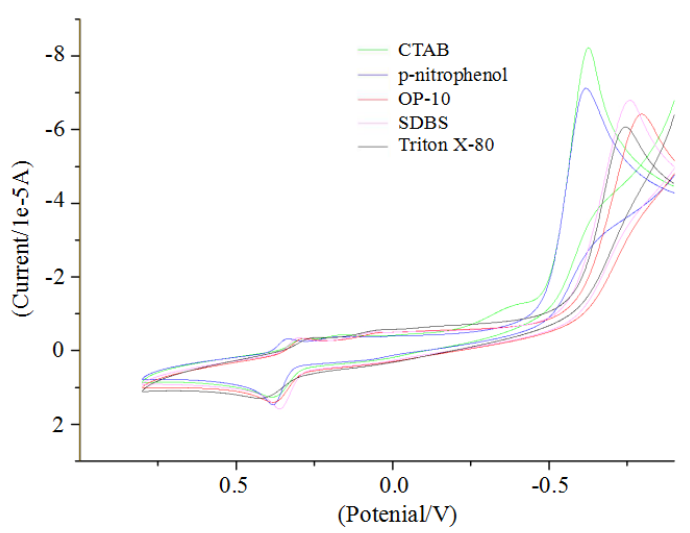

Figure 1. Effects of different surfactants on the reduction peak of p-nitrophenol

As shown in Figure 1, the largest reduction peak of pnitrophenol was observed in the presence of the CTAB. This may be attributable to the fact that, the CTAB boasts the fastest redox reaction among the above surfactants, owing to its suitable length of hydrophobic chain and proper amount of adsorption on the electrode surface. By contrast, the presence of several other surfactants suppressed the peak current, especially emulsifier OP-10.

\subsection{The effects of different surfactants on reduction peak current of p-nitrophenol}

\subsubsection{Cationic surfactant}

The effect of the CTAB concentration on the peak current and potential of p-nitrophenol reduction is illustrated in Figure 2. It can be seen that, with the initial growth in the CTAB concentration, the reduction peak current of nitrophenol increased rapidly. A possible reason is that the modified layer on the electrode is very thin or the electrode is not completely modified by CTAB when the concentration of CTAB is low.

When the CTAB concentration reached the range of $3 \times 10^{-4}$ $\sim 6 \times 10^{-4} \mathrm{~mol} / \mathrm{L}$, the reduction peak current of $\mathrm{p}$-nitrophenol tended to be stable after a huge increase. This may be the result of the micelle effect of the CTAB: the peak current of $p$ - 
nitrophenol changes drastically around the critical micelle concentration (CMC) of the surfactant.

Once the CTAB concentration reached the CMC, the pnitrophenol was surrounded, so that a slightly reduced yet stable amount of p-nitrophenol could reach the electrode surface. Then, the peak current was slightly reduced, and the peak potential was deeply suppressed by the electrostatic effect of CTAB and P-nitrophenol. The CMC of the CTAB concentration is about $3 \times 10^{-4}$ at $20{ }^{\circ} \mathrm{C}$. That is why the reduction peak current of $\mathrm{p}$-nitrophenol reached the valley at the CTAB concentration of $3 \times 10^{-4} \mathrm{~mol} / \mathrm{L}$.

After the CTAB concentration increased to the range of $7 \times 10^{-4} \sim 8 \times 10^{-4} \mathrm{~mol} / \mathrm{L}$, the peak current showed a slight decline, because too much nitrophenol is adsorbed on the long chain of water and the redox reaction proceeds completely.
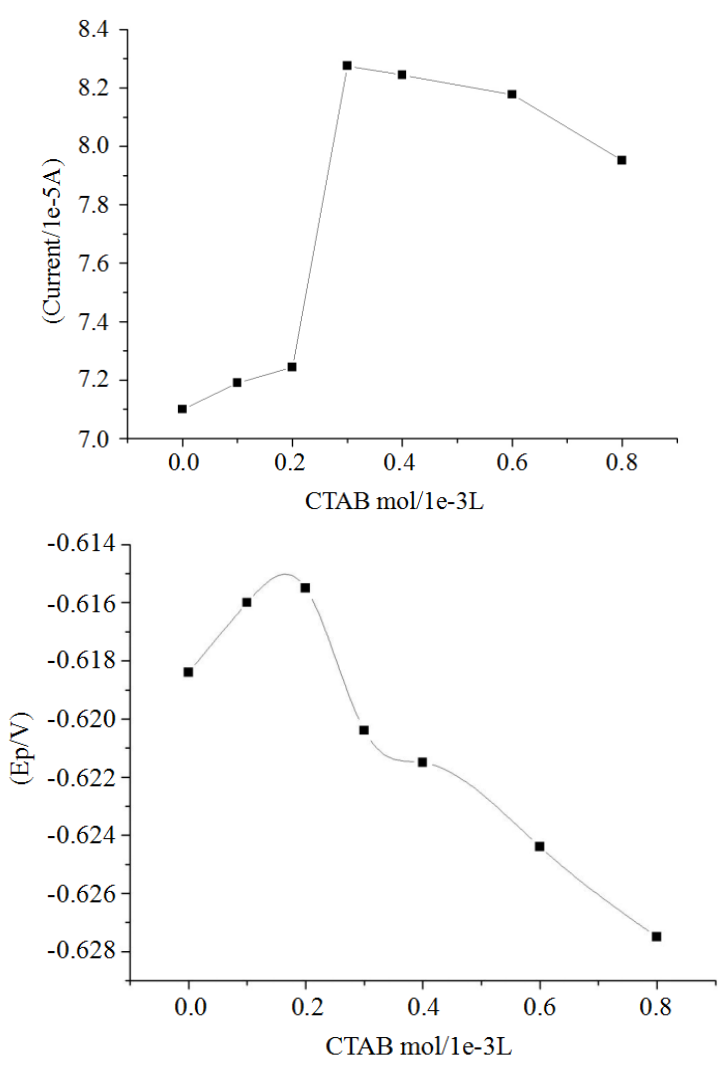

Figure 2. Effect of CTAB concentration on the peak current and peak potential of $\mathrm{p}$-nitrophenol reduction

\subsubsection{Anionic surfactant}

The effect of the SDBS concentration on the peak current and potential of p-nitrophenol reduction is presented in Figure 3. It can be seen that, with the initial growth in the SDBS concentration, the reduction peak current of nitrophenol decreased deeply, and the reduction peak potential of nitrophenol plunged even more drastically. These trends are resulted from the thin or incomplete modified layer on the electrode at a low concentration of the SDBS.

When the SDBS concentration reached the range of $6 \times 10^{-4}$ $\sim 1.2 \times 10^{-3} \mathrm{~mol} / \mathrm{L}$, the reduction peak current of $\mathrm{p}$-nitrophenol remained basically stable, while the reduction peak potential showed a gradual decline. These trends could be attributed to the electrostatic adsorption with SDBS and p-nitrophenol, making p-nitrophenol unable to reach the electrode surface.

Once the SDBS concentration reached the CMC, the pnitrophenol was surrounded, leaving only a slightly reduced yet stable amount of p-nitrophenol to reach the electrode surface. As a result, the peak current was slightly reduced, while the peak potential had a deep decline. The reduction peak current of p-nitrophenol reached the valley at the SDBS concentration of $1.3 \times 10^{-3} \mathrm{~mol} / \mathrm{L}$.
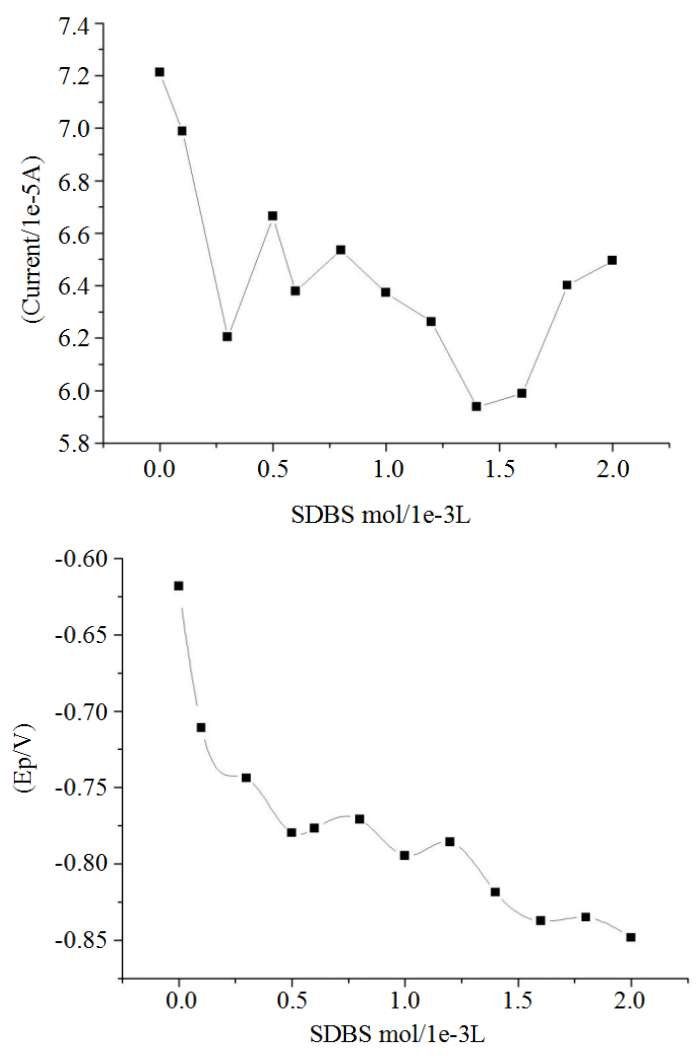

Figure 3. Effect of SDBS concentration on the peak current and peak potential of $\mathrm{p}$-nitrophenol reduction

\subsubsection{Nonionic surfactants}

The effect of Tween 80 concentration on the peak current and peak potential of $\mathrm{p}$-nitrophenol reduction is displayed in Figure 4. It can be seen that, with the concentration of Tween 80 , the reduction peak current of p-nitrophenol started to decrease. This is because the electrode only has a very thin modified layer or not completely modified at a low Tween 80 concentration.

When the Tween 80 concentration climbed to the range of $7 \times 10^{-5} \sim 8 \times 10^{-5} \mathrm{~mol} / \mathrm{L}$, the reduction peak current of $\mathrm{p}$ nitrophenol remained basically stable, possibly due to the micelle effect with Tween 80 .

Once Tween 80 reached the $\mathrm{CMC}$, the p-nitrophenol was surrounded, such that only a small yet steady amount of pnitrophenol could reach the electrode surface. This brought a steady fluctuation of the reduction peak current. The reduction peak current of p-nitrophenol reached the valley at the Tween 80 concentration of $1.3 \times 10^{-3} \mathrm{~mol} / \mathrm{L}$.

Meanwhile, the absolute value of p-nitrophenol's reduction peak potential increased as the Tween 80 concentration grew from zero to $8.1 \times 10^{-5} \mathrm{~mol} / \mathrm{L}$, and moved rapidly towards the negative direction as the concentration changed from $1 \times 10^{-5}$ $\mathrm{mol} / \mathrm{L}$ to $3 \times 10^{-5} \mathrm{~mol} / \mathrm{L}$. The reason for this trend might be the steady increase in the modified layer or the complete modification of the electrode by Tween 80 . In this case, the pnitrophenol can reach the electrode surface under the high potential.

With further increase in the Tween 80 concentration, the reduction peak potential of $\mathrm{p}$-nitrophenol shifted to the 
negative direction. This is because Tween 80 arrived at the $\mathrm{CMC}$ and enclosed the p-nitrophenol, reducing the amount of p-nitrophenol reaching the electrode surface. Under the electrostatic effect of Tween 80 and p-nitrophenol, it is difficult for p-nitrophenol to break through the enclosure of Tween 80. The absolute value of the peak potential will increase once p-nitrophenol reaches the electrode surface.
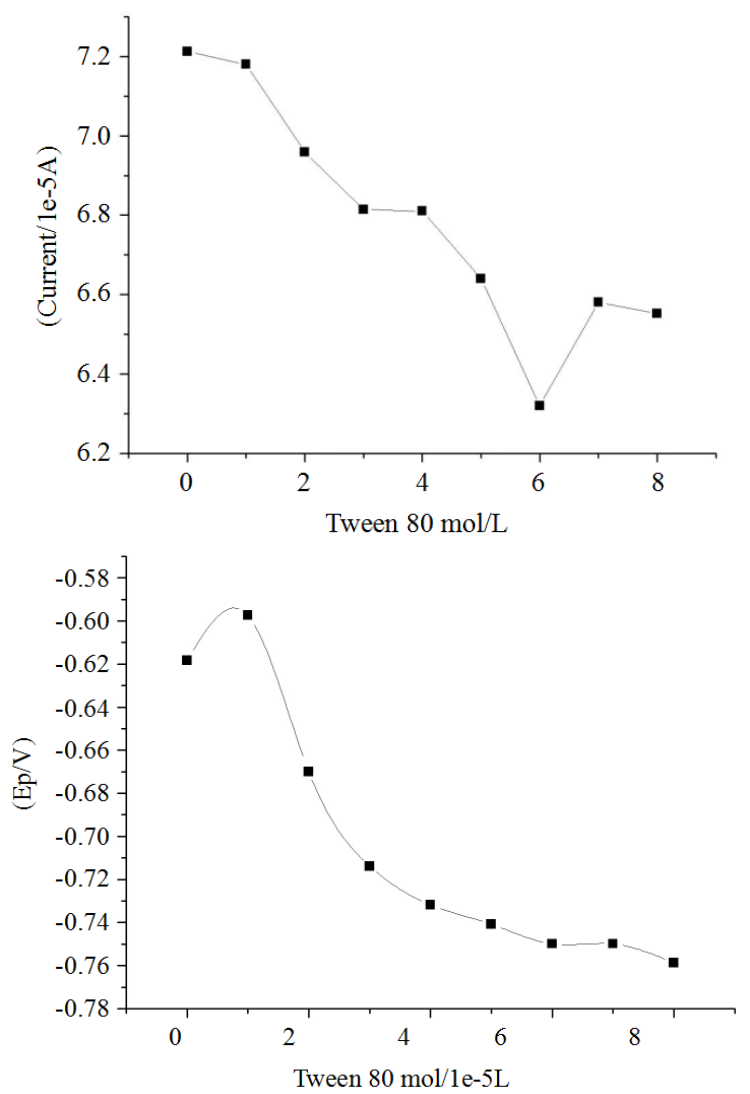

Figure 4. Effect of Tween 80 concentration on the peak current and peak potential of $\mathrm{p}$-nitrophenol reduction

Figure 5 describes the effect of OP-10 concentration on the peak current and peak potential of p-nitrophenol reduction. It can be seen that the reduction peak current of nitrophenol began to decrease with the initial growth in OP-10 concentration, and reached the valley at the concentration of $8 \times 10^{-4} \mathrm{~mol} / \mathrm{L}$, owing to the micelle effect of OP- 10 .

Once OP-10 reached the CMC, it covered up the pnitrophenol. Then, only a steady amount of p-nitrophenol could reach the electrode surface, leading to a stable peak current. The reduction peak current of $\mathrm{p}$-nitrophenol reached the valley at the OP-10 concentration of $8 \times 10^{-4} \mathrm{~mol} / \mathrm{L}$.

The peak current at $2 \times 10^{-4} \mathrm{~mol} / \mathrm{L}$ changed abrupted because the glassy carbon electrode was not ground and contained the previous reactant, which blocked the reaction of nitrophenol.

Meanwhile, as the OP-10 concentration increased from zero to $2 \times 10^{-5} \mathrm{~mol} / \mathrm{L}$, the reduction peak potential of $\mathrm{p}$-nitrophenol moved rapidly towards the negative direction. The reason for this trend might be the steady increase in the modified layer or the complete modification of the electrode by Tween 80 . In this case, the p-nitrophenol can reach the electrode surface under the high potential.

When the OP-10 concentration changed from $3 \times 10^{-5} \mathrm{~mol} / \mathrm{L}$ to $2 \times 10^{-4} \mathrm{~mol} / \mathrm{L}$, the reduction peak potential of $\mathrm{p}$-nitrophenol moved slowly in the negative direction. This is because OP-10 arrived at the $\mathrm{CMC}$ and enclosed the p-nitrophenol, reducing the amount of p-nitrophenol reaching the electrode surface. Under the electrostatic effect of OP-10 and p-nitrophenol, it is difficult for $\mathrm{p}$-nitrophenol to break through the enclosure of OP-10. The absolute value of the peak potential will increase after p-nitrophenol reaches the electrode surface.
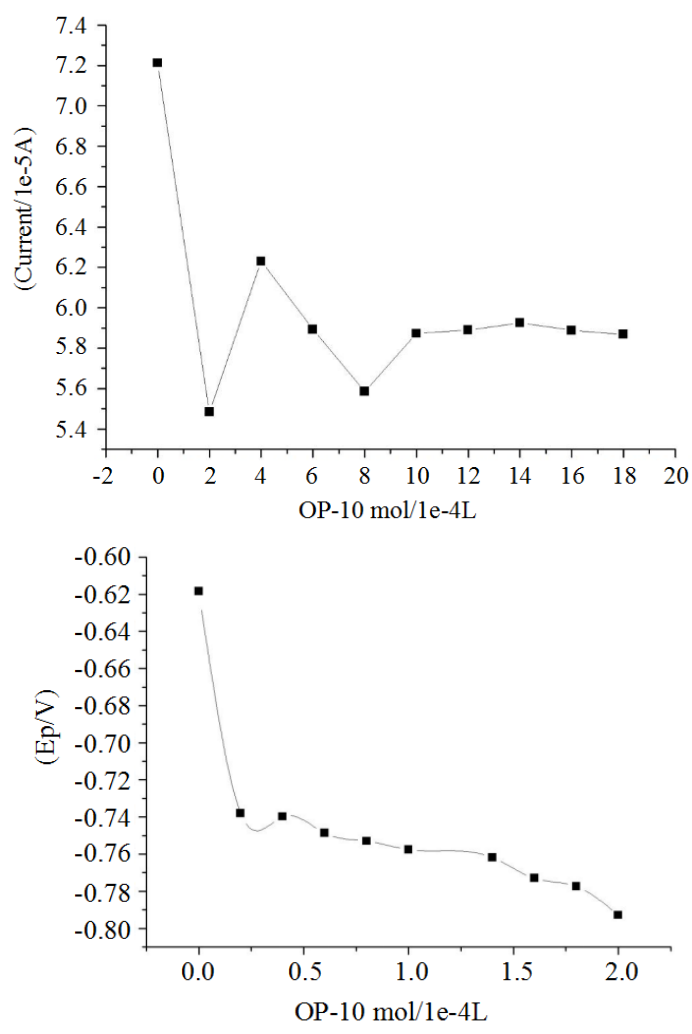

Figure 5. Effect of OP-10 concentration on the peak current and peak potential of $\mathrm{p}$-nitrophenol reduction

\section{CONCLUSIONS}

This paper fully compares the electroreduction of $\mathrm{p}$ nitrophenol by different surfactant-modified chemical electrodes. The main findings are as follows:

First, the cationic surfactant (CTAB) sensitized and reduced the peak current, reaching the optimal reduction effect at the concentration of $2.95 \times 10^{-4} \mathrm{~mol} / \mathrm{L}\left(8.294 \times \mathrm{e}^{-5} \mathrm{~A}\right)$.

Second, the anionic surfactant (SDBS) and nonionic surfactants (Tween 80, OP-10) reduced the peak current, and the reduction effect is related to the micelle effect of the surfactants, density of electron cloud and the structure of the active agent.

Third, the surfactants differ in their influence on the reduction peak potential of $\mathrm{p}$-nitrophenol on the glassy carbon electrode: the cationic surfactant suppressed the reduction peak potential at concentrations of $0 \sim 2 \times 10^{-4} \mathrm{~mol} / \mathrm{L}$, while the other three surfactants cannot reduce the reduction peak potential.

To sum up, the CTAB was selected as the most sensitive material for detecting p-nitrophenol on electrode surface. The research data provide a valuable reference for the design of $\mathrm{p}$ nitrophenol sensors.

\section{ACKNOWLEDGEMENT}

The authors would like to thank the National Natural 
Science Foundation of China (No. 21671132), and Colleges and universities in Henan province key scientific research project(No. 18A480005), and the teaching masters breeding project of North China University of Water Resources and Electric Power (2017), and Henan engineering technology research center (No. 211[2016]-high-tech35), Henan innovative science and technology team (No. C20150017).

\section{REFERENCES}

[1] Azzam, E.M., Fathy, N.A., El-Khouly, S.M., Sami, R. M. (2019). Enhancement the photocatalytic degradation of methylene blue dye using fabricated CNTs/TiO2/AgNPs/Surfactant nanocomposites. Journal of Water Process Engineering, 28: 311-321. https://doi.org/10.1016/j.jwpe.2019.02.016

[2] Dos Santos, A., Viante, M.F., Pochapski, D.J., Downs, A.J., Almeida, C.A.P. (2018). Enhanced removal of pnitrophenol from aqueous media by montmorillonite clay modified with a cationic surfactant. Journal of Hazardous Materials, 355: 136-144. https://doi.org/10.1016/j.jhazmat.2018.02.041

[3] Mei, X., Liu, J., Guo, Z.W., Li, P.P., Bi, S.Q., Wang, Y., Yang, Y., Shen, W.T., Wang, Y.H., Xiao, Y.Y., Yang, X., Zhou, B.C., Liu, H., Wu, S. (2019). Simultaneous pnitrophenol and nitrogen removal in PNP wastewater treatment: Comparison of two integrated membraneaerated bioreactor systems. Journal of Hazardous Materials, 363: 99-108. https://doi.org/10.1016/j.jhazmat.2018.09.072

[4] Park, Y., Ayoko, G.A., Frost, R.L. (2011). Characterisation of organoclays and adsorption of $\mathrm{p}$ nitrophenol: Environmental application. Journal of Colloid and Interface Science, 360(2): 440-456. https://doi.org/10.1016/j.jcis.2011.04.085

[5] Hengge, A.C., Tobin, A.E., Cleland, W.W. (1995). Studies of transition-state structures in phosphoryl transfer reactions of phosphodiesters of p-nitrophenol. Journal of the American Chemical Society, 117(22): 5919-5926. https://doi.org/10.1021/ja00127a003

[6] Hu, K., Bradshaw, J.S., Pastushok, V.N., Krakowiak, K.E., Dalley, N.K., Zhang, X.X., Izatt, R.M. (1998). Synthesis of proton-ionizable p-nitrophenol-containing tetraazacrown and diazadithiacrown ethers from an aromatic building block prepared via the Einhorn reaction. The Journal of Organic Chemistry, 63(14): 4786-4791. https://doi.org/10.1021/jo980414z

[7] Pradhan, A.A., Gogate, P.R. (2010). Removal of pnitrophenol using hydrodynamic cavitation and Fenton chemistry at pilot scale operation. Chemical Engineering Journal, 156(1): 77-82. https://doi.org/10.1016/j.cej.2009.09.042

[8] Ji, Q., Li, J., Xiong, Z., Lai, B. (2017). Enhanced reactivity of microscale $\mathrm{Fe} / \mathrm{Cu}$ bimetallic particles $(\mathrm{mFe} / \mathrm{Cu})$ with persulfate (PS) for p-nitrophenol (PNP) removal in aqueous solution. Chemosphere, 172: 10-20. https://doi.org/10.1016/j.chemosphere.2016.12.128

[9] Hasan, Z., Cho, D.W., Chon, C.M., Yoon, K., Song, H. (2016). Reduction of p-nitrophenol by magnetic Cocarbon composites derived from metal organic frameworks. Chemical Engineering Journal, 298: 183190. https://doi.org/10.1016/j.cej.2016.04.029

[10] Álvarez-Torrellas, S., Martin-Martinez, M., Gomes, H.T.,
Ovejero, G., García, J. (2017). Enhancement of pnitrophenol adsorption capacity through N2-thermalbased treatment of activated carbons. Applied Surface Science, 414 : 424-434. https://doi.org/10.1016/j.apsusc.2017.04.054

[11] Ali, Z.I., Bekhit, M., Sokary, R., Afify, T.A. (2019). Radiation synthesis of copper sulphide/poly(vinyl alcohol) nanocomposites films: an efficient and reusable catalyst for $p$-nitrophenol reduction. Journal of Environmental Analytical Chemistry, 99: 1313-1324. https://doi.org/10.1080/03067319.2019.1619717

[12] Baran, T., Nasrollahzadeh, M. (2019). Facile synthesis of palladium nanoparticles immobilized on magnetic biodegradable microcapsules used as effective and recyclable catalyst in Suzuki-Miyaura reaction and pnitrophenol reduction. Carbohydrate Polymers, 222: 115029. https://doi.org/10.1016/j.carbpol.2019.115029

[13] Bae, S., Gim, S., Kim, H., Hanna, K. (2016). Effect of $\mathrm{NaBH} 4$ on properties of nanoscale zero-valent iron and its catalytic activity for reduction of p-nitrophenol. Applied Catalysis B: Environmental, 182: 541-549. https://doi.org/10.1016/j.apcatb.2015.10.006

[14] Bhattacharjee, A., Ahmaruzzaman, M. (2016). CuO nanostructures: facile synthesis and applications for enhanced photodegradation of organic compounds and reduction of p-nitrophenol from aqueous phase. RSC Advances, 6(47): 41348-41363. https://doi.org/10.1039/c6ra03624d

[15] Basahel, S.N., Mokhtar, M., Alsharaeh, E.H., Ali, T.T., Mahmoud, H.A., Narasimharao, K. (2016). Photocatalytic degradation of p-nitrophenol in aqueous suspension by using graphene $/ \mathrm{ZrO}_{2}$ catalysts. Nanoscience and Nanotechnology Letters, 8(5): 448-457. https://doi.org/10.1166/nnl.2016.2172

[16] de Oliveira, F., Nascimento, L., Calado, C., Meneghetti, M., da Silva, M. (2016). Aqueous-phase catalytic chemical reduction of p-nitrophenol employing soluble gold nanoparticles with different shapes. Catalysts, 6(12): 2073-4344. https://doi.org/10.3390/catal6120215

[17] Vijayalakshmi, A., Vidyavathy, B., Vinitha, G. (2016). Crystal structure, growth and nonlinear optical studies of isonicotinamide p-nitrophenol: A new organic crystal for optical limiting applications. Journal of Crystal Growth, 448: $82-88$. https://doi.org/10.1016/j.jcrysgro.2016.05.002

[18] Jović, A., Đorđević, A., Čebela, M., Simatović, I.S., Hercigonja, R., Šljukić, B. (2016). Composite zeolite/carbonized polyaniline electrodes for $p$ nitrophenol sensing. Journal of Electroanalytical Chemistry, 778: 137-147. https://doi.org/10.1016/j.jelechem.2016.08.025

[19] Rathika, A., Prasad, L.G., Raman, R.G. (2016). Physicochemical properties of dimethylammonium $p$ nitrophenolate-p-nitrophenol: A nonlinear optical crystal. Physica B: Condensed Matter, 485: 29-34. https://doi.org/10.1016/j.physb.2016.01.001

[20] Dos Santos, A., Viante, M.F., Pochapski, D.J., Downs, A.J., Almeida, C.A.P. (2018). Enhanced removal of pnitrophenol from aqueous media by montmorillonite clay modified with a cationic surfactant. Journal of Hazardous Materials, 355: 136-144. https://doi.org/10.1016/j.jhazmat.2018.02.041

[21] Subashchandrabose, S.R., Venkateswarlu, K., Krishnan, K., Naidu, R., Lockington, R., Megharaj, M. (2018). 
Rhodococcus wratislaviensis strain: An efficient pnitrophenol degrader with a great potential for bioremediation. Journal of Hazardous Materials, 347: 176-183. https://doi.org/10.1016/j.jhazmat.2017.12.063

[22] Vervald, A.M., Laptinskiy, K.A., Burikov, S.A., Laptinskaya, T.V., Shenderova, O.A., Vlasov, I.I., Dolenko, T.A. (2019). Nanodiamonds and surfactants in water: Hydrophilic and hydrophobic interactions. Journal of Colloid and Interface Science, 547: 206-216. https://doi.org/10.1016/j.jcis.2019.03.102

[23] Chen, J., Hu, X.Y., Fang, Y., Jin, G.Y., Xia, Y.M. (2019). What dominates the interfacial properties of extended surfactants: Amphipathicity or surfactant shape. Journal of Colloid and Interface Science, 547: 190-198. https://doi.org/10.1016/j.jcis.2019.04.002
[24] Karthick, A., Roy, B., Chattopadhyay, P. (2019). A review on the application of chemical surfactant and surfactant foam for remediation of petroleum oil contaminated soil. Journal of Environmental Management, 243: 187-205. https://doi.org/10.1016/j.jenvman.2019.04.092

[25] Garcia, M.T., Ribosa, I., Kowalczyk, I., Pakiet, M., Brycki, B. (2019). Biodegradability and aquatic toxicity of new cleavable betainate cationic oligomeric surfactants. Journal of Hazardous Materials, 371: 108114. https://doi.org/10.1016/j.jhazmat.2019.03.005

[26] Trinh, T.A., Han, Q., Ma, Y., Chew, J.W. (2019). Microfiltration of oil emulsions stabilized by different surfactants. Journal of Membrane Science, 579: 199-209. https://doi.org/10.1016/j.memsci.2019.02.068 